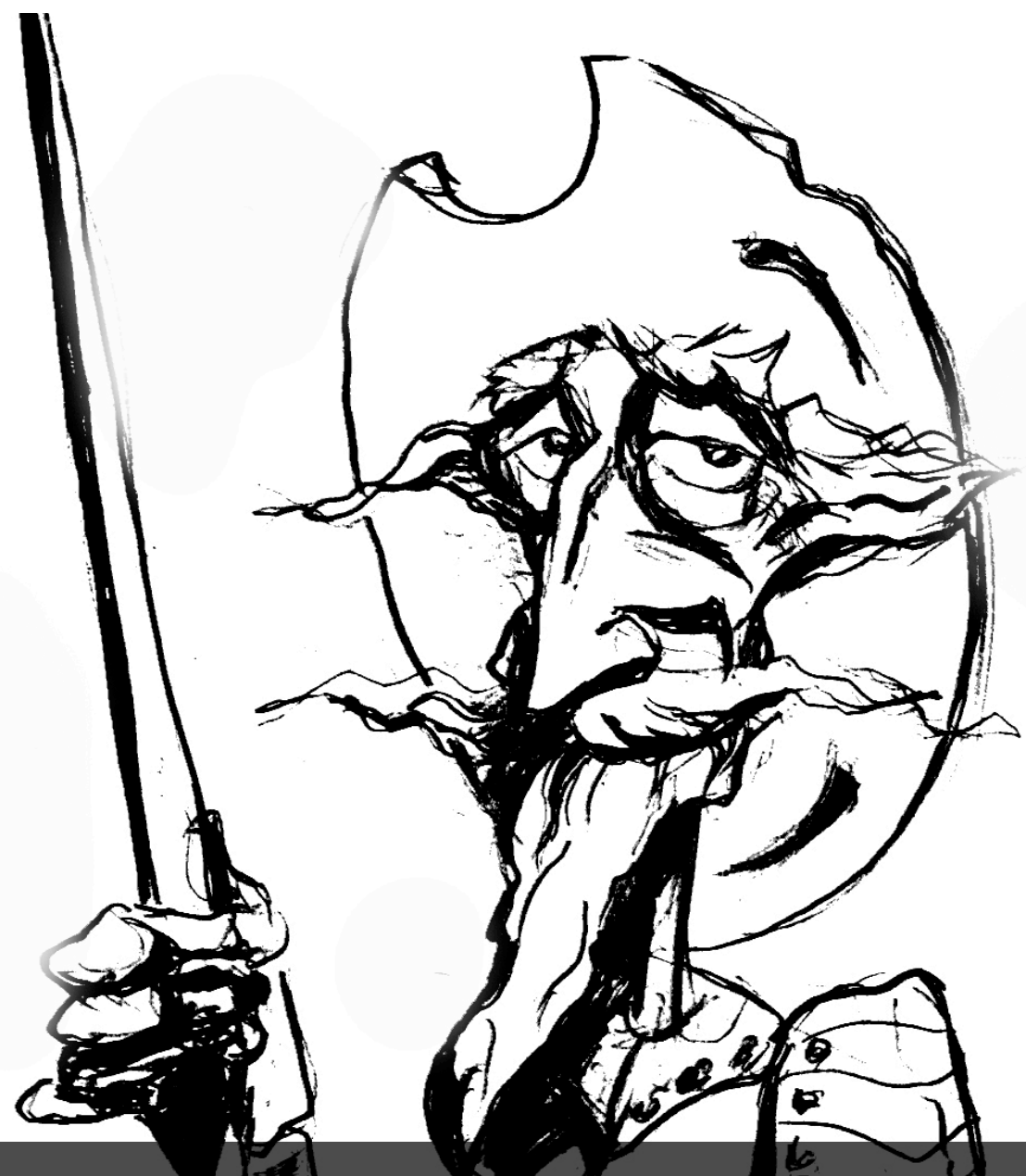

La renegociación de la unión desde la perspectiva litúrgica. Tucumán, 1816-1819

[Ana Wilde] 


\section{La renegociación de la unión desde la perspectiva litúrgica. Tucumán, 1816-1819*}

The Renegotiation of the Union from the Liturgical Perspective. Tucumán, 1816-1819.

\section{Resumen}

A mediados de la década de 1810, la guerra independentista y la unión entre las provincias rioplatenses zozobraban. En ese momento, se negoció la reunión de un Congreso en Tucumán para definir el curso de la conflagración y la política de la región. Cumplido su objetivo de máxima -la independencia-, la asamblea acordó una liturgia política que naturalizara la imagen de orden y unión. Sin embargo, esta liturgia presentó también tensiones e imágenes en conflicto. El objetivo de este trabajo es -a través del estudio de las celebraciones y los discursos políticos públicos- recrear las imágenes, conflictos y diagnósticos que se construyeron en la escena tucumana significando la coyuntura política del período de cara al resto de las Provincias Unidas.

\section{Palabras Clave}

Liturgia política - declaración de Independencia - Tucumán - revolución - representaciones
ANA WILDE

\section{Abstract}

Towards the middle of the 1810 's decade, the Independence wars and the union between the provinces of the Rio de la Plata were weakened. A Constitutive Congress was held in Tucumán in order to define the future of the armed conflicts and to arrange a normative frame for the local politics. Having accomplished their main objective -the independence-, the assembly arranged a politic liturgy so as to create an image of order and union. But, this liturgy also presented contradictory representations. The purpose of this investigation is to recreate the meaning of the celebrations and speeches that, from the Tucuman's public opinion, symbolized this juncture.

\section{Key words}

Politic liturgy - declaration of Independence Tucumán - revolution -representations

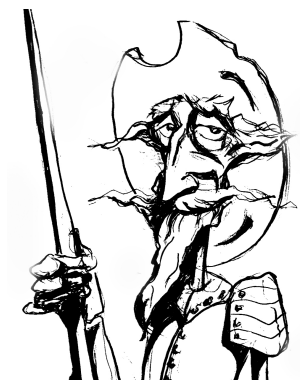

Recibido con pedido de publicación el 10 de febrero de 2016

Aceptado para su publicación el 25 de abril de 2016

Versión definitiva recibida el 30 de mayo de 2016

Ana Wilde, Universidad Nacional de Rosario (UNR), Universidad Nacional de Tucumán (UNT), Argentina; e-mail: anitawilde@yahoo.com

\footnotetext{
* Este trabajo tuvo una primera presentación en el I Congreso Internacional de Estudios Latinoamericanos de Posgrado y I Encuentro Nacional de Cátedras de Historia de América, organizado por la Fac. de Fil. y Letras de la UNT, en noviembre de 2015 (Tafí del Valle, Tucumán, Argentina) Agradezco especialmente los comentarios que entonces realizaron Facundo Nanni, Alejandro Morea, Valentina Ayrolo, Fabián Herrero y Gabriela Caretta. Agradezco, asimismo, a los evaluadores anónimos de la revista.
}

Esta obra se publica bajo licencia Creative Commons. Atribución-NoComercial-CompartirIgual 4.0 Internacional

Wilde, Ana "La renegociación de la unión desde la perspectiva litúrgica. Tucumán, 1816-1819", Prohistoria, Año XIX, núm. 25, jun. 2016, pp. 29-51. 
En 1814, las monarquías europeas retornaban al poder con renovadas pretensiones absolutistas. Fernando VII ponía coto a los liberales en la Península y enviaba refuerzos militares para sofocarlos en América. En Tucumán, el Ejército Auxiliar del Norte se preparaba para un tercer avance sobre el Perú a pesar del desamparo del Director Carlos María de Alvear. En vista de ello, el General José Rondeau se declaró en rebeldía y emprendió la campaña sin su apoyo. En una orfandad más extrema se hallaban las huestes del gobernador salteño Martín Miguel de Güemes, que si bien lograba contener al enemigo en la zona salto-jujeña, no conseguía evacuarlo. En Cuyo se preparaba el Ejército de los Andes, también con escasos apoyos del gobierno central. En consecuencia, el jefe militar y gobernador de Mendoza, José de San Martín, junto al cabildo local decidieron abstenerse de tratar con Buenos Aires cualquier otro asunto que no fuera la campaña libertadora de Chile. Por su lado, la "Liga de Pueblos Libres" -comprendida por la Banda Oriental, Corrientes, Entre Ríos y Santa Fe-, estaba bajo el liderazgo de José Gervasio Artigas y en pie de guerra contra el Directorio en defensa de las autonomías provinciales. Córdoba también estaba distanciada del gobierno central y proclive al proyecto artiguista. Tal era el panorama rioplatense cuando el Director Alvear tomó la decisión de evacuar Montevideo e invadir Santa Fe. Esta determinación precipitó su caída en abril de 1815. Acéfalo el gobierno central, el Ayuntamiento porteño reasumió el mando como lo hizo en 1810, pero en un escenario más complejo: el Litoral y Córdoba se desenvolvían con independencia y el resto de las provincias asistían desengañadas a este desenlace barajando la posibilidad de aliarse entre sí sin concederle a Buenos Aires el rol directivo.

El presente trabajo tiene como punto de partida este momento de suma fragilidad; el cual intentó revertirse mediante la renegociación del vínculo interprovincial. Esto implicó -entre otras medidas-, la construcción de un dispositivo litúrgico que, desde una determinada representación pública del pasado y proyección hacia el futuro, difundió una imagen de orden, estabilidad y unión. No obstante, estas instancias constituyeron también ocasiones en las que se visualizó tensiones, conflictos e incertidumbres que concurrieron a desestabilizar o a anteponer condiciones al mantenimiento de aquella unión renegociada que, por otra parte, terminará estallando a fines de 1819. Durante ese tiempo, Tucumán desempeñó un rol clave; como escenario del pacto de integración y como modelo de la retórica y los rituales que le dieron encarnadura; pero también fue la primera ciudad en quebrantar ese pacto de unión sellado con el manifiesto de agosto de 1816 y que su liturgia política había intentado convertir en relato canónico.

Con "liturgia política" referimos a toda práctica escrita, oral o gestual que manifestó cierta regularidad en su celebración y atendió al objetivo de consensuar -en el sentido de sentir juntos- un determinado relato del pasado y 
del futuro comunitario, expresando un ordenamiento e identidad políticas y dando legitimidad a quienes lo representaban. Ya en la década de 1980, Norbert Elías utilizaba el concepto de liturgia, no solo para referirse a lo religioso, sino también a los protocolos y ceremonias que servían para distinguir y distanciar a las élites del resto de la sociedad. ${ }^{1}$ En el contexto historiográfico hispanoamericano más reciente, Jaime Valenzuela Márquez utiliza la idea de "liturgias del poder" para referir al conjunto de apariencias, etiquetas y protocolos que en las ceremonias públicas coadyuvaban a vehicular la consolidación del poder real y el control sobre la opinión pública en Chile. En un sentido no muy distinto, otros autores utilizan también este concepto para referir a los rituales políticos de algún período específico como, por ejemplo, lo hace Pablo Ortemberg al caracterizar la "liturgia bolivariana" en el Perú entre los años 1823 y 1826. ${ }^{2}$ Estos estudios, entre otros, ${ }^{3}$ consideran a la esfera de las representaciones públicas del poder una dimensión constitutiva e incluso performativa de la política, en la que se dan decisivas pujas por el poder, se representan pactos, delimitan zonas de influencia y proclaman agendas. Con estas obras compartimos un supuesto básico: que las revoluciones de independencia hispanoamericanas lejos de constituir un mero proceso de secesión política, comportó un complejo y profundo resquebrajamiento y recomposición del orden simbólico. Sobre estos temas, para el caso del Río de la Plata, contamos con el trabajo de Lía Munilla sobre las fiestas cívicas de Buenos Aires entre 1810 y 1835, analizadas desde la doble perspectiva de la historia política y la historia del arte. Por otro lado, la obra de Geneviève Verdo articula varios aspectos de la vida política de las ciudades de Salta, Córdoba, Mendoza y Tucumán, entre los cuales se cuenta el de la representación pública de la política durante la década de 1810. Más recientemente, Gabriela Caretta

1 ELÍAS, Norbet La sociedad cortesana, FCE, México, 1982; El proceso de la civilización. Investigaciones sociogenéticas y psicogenéticas, FCE, México, 1988.

2 VALENZUELA MARQUEZ, Jaime La liturgia del poder. Celebraciones públicas y estrategias persuasivas en Chile colonial (1609-1709), DIBAM-Centro de Investigaciones Diego Barros Arana/LOM, Santiago, 2001. ORTEMBERG, Pablo Rituales del poder en Lima (1735-1828). De la monarquía a la república, ed. Pontificia Universidad Católica del Perú, Lima, 2014.

3 CALDERÓN, María Teresa y THIBAUD, Clément La majestad de los pueblos en la Nueva Granada y Venezuela (1780-1832), Universidad Externado de Colombia-Taurus, Bogotá, 2010; VALENZUELA MÁRQUEZ, Jaime Fiesta, rito y política: del Chile borbónico al republicano, DIBAMCentro de Investigaciones Barros Arana, Santiago, 2014; ZÁRATE TOSCANO, Verónica "La conformación de un calendario festivo en México en el siglo XIX", en Erika Pani y Alicia Salmerón (Coord.) Conceptuar lo que se ve. François Xavier Guerra, historiador. Homenaje, Instituto Mora, México, 2004, pp.182-214. Ver también la compilación de ORTEMBERG, Pablo (Dir.) El origen de las fiestas patrias. Hispanoamérica en la era de las independencias, Ed. Prohistoria, Rosario, 2013. 
incursionó sobre la dimensión simbólica y política de los funerales entre 1820 y 1850.4

\section{El "nacimiento" de la Independencia en Tucumán}

Luego del desplazamiento del Director Alvear en abril de 1815, el Cabildo de Buenos Aires, pretendiendo desandar el camino político que le había enajenado al gobierno central el apoyo de casi todas las jurisdicciones rioplatenses, designó a Rondeau como Director provisorio ya que en torno suyo giraba el consenso del Interior. Como este declinó el cargo por encontrarse en campaña en el Alto Perú, se optó por el coronel que había depuesto al impopular Alvear, Ignacio Álvarez Thomas. También -a través de la Junta de Observación- el ayuntamiento porteño aprobó un reglamento que limitaba las atribuciones del Director y ampliaba los cargos electivos permitiendo, por ejemplo, que los ciudadanos provinciales eligieran a sus propios gobernadores. Además, consintió la reunión de un nuevo congreso fuera de Buenos Aires. La cita sería en Tucumán.

La elección de esta ciudad no fue casual. Casi todas las demás le eran hostiles a la ex capital, en cambio, con el gobierno tucumano conservaba buenas relaciones y resultaba confiable al resto de las jurisdicciones. La locación tenía la ventaja de disociar la autoridad del Congreso de la primacía de Buenos Aires. Posiblemente por ello Córdoba decidió finalmente participar; aunque el resto de la Liga artiguista no asistió. Para las autoridades tucumanas, tal designación fue un gran honor pero también una abrumadora tarea. No hay registro de que el resto de las ciudades haya colaborado en la realización del Congreso y Tucumán era, además, base operativa del Ejército del Norte y centro de

\footnotetext{
${ }^{4}$ MUNILLA, Lía Celebrar y gobernar: un estudio de las fiestas cívicas en Buenos Aires, 1810-1835, Miño y Dávila Editores, Buenos Aires, 2013. VERDO, Geneviève L'indépendance argentine entre cités et nation, Publications de la Sorbonne, París, 2006; “La Bannière, Le Sabre Et Le Goupillon: Les Cérémonies Patriotiques Dans L'indépendance Du Río De La Plata (1808-1821)", Revue Historique, CCXCVI/2, núm. 600, París, 1997, pp. 401-429; CARETTA, Gabriela Y el Cielo se tiñó de rojo... Muerte heroica y Más allá en las Provincias Des-Unidas del Río de la Plata (1820-1852), en Locus. Revista de História Departamento de História e do Programa de Pós-Graduação em História da Universidade Federal de Juiz de Fora, Minas Gerais, en prensa; CARETTA, Gabriela y ZACCA, Isabel "Itinerarios de un cuerpo. Los segundos funerales de Güemes en el proceso de construcción de memorias", en Sara Mata y Zulma Palermo (comps.) Travesía discursiva: representaciones identitarias en Salta (siglos XVIII-XIX), Prohistoria Ediciones, Rosario, 2011, pp. 71-91; CARETTA, Gabriela "Ciudades de muertos y funerales de Estado. Paradojas en la reconstrucción de la religión y la política entre los Borbones y los gobiernos provinciales", en Valentina Ayrolo, María Elena Barral y Roberto Di Stefano (Coords.) Catolicismo y secularización. Argentina en la primera mitad del siglo XIX, Biblos, Buenos Aires, 2012, pp. 93-113.
} 
abastecimiento y recepción de heridos y emigrados; afanes que se intensificaron tras la derrota de Sipe Sipe en noviembre de $1815 .{ }^{5}$

\section{Celebraciones inaugurales del Congreso}

A pesar de las dificultades, el 24 y 25 de marzo de 1816 se celebró la inauguración del Congreso en Tucumán. Los días 24 y 25 se escogieron en honor a la reciente tradición de Mayo. Además, el 25 de marzo se celebraba la encarnación de "Nuestro Señor Jesucristo", inmejorable augurio de la "encarnación" de la soberanía nacional en los representantes de los pueblos. ${ }^{6}$ Como observaremos a lo largo de este trabajo, la matriz religiosa cristiana presente en la cultura política de estas comunidades fue un elemento fundamental para significar la coyuntura política de comienzos del siglo XIX. La Iglesia constituía uno de los principales y más consolidados paradigmas sociales de la época, sus ministros representaban el ideal de estabilidad, orden, cohesión interna, obediencia, abnegación, formación y religiosidad. Como tradicionales depositarios de las tareas de educación y control de las personas, los clérigos jugaron un rol clave en el interior de las comunidades locales en las que nacieron y/o actuaron, desempeñándose como influyentes referentes políticos; justamente, de los treinta y tres diputados que reunió este Congreso en 1816 , trece eran clérigos. ${ }^{7}$

\footnotetext{
${ }^{5}$ El tenso clima social en Tucumán los meses previos al congreso fue consignado por: ÁVILA, Julio La ciudad arribeña. Tucumán 1810-1816. Reconstrucción histórica, Colección Nuestros Clásicos, Universidad Nacional de Tucumán, Tucumán, 2003, p. 386 y por el ex jesuita Villafañe (FURLONG, Guillermo "Diego León Villafañe y sus cartas referentes a la Revolución Argentina", Boletín de la Academia Nacional de la Historia, Año XXXVIII, núm. 31, Buenos Aires, 1960, pp. 87-212).

${ }^{6}$ El Redactor del Congreso Nacional, núm. 1, p.1, reimpresión facsimilar, Ed. Docencia-Fundación Hernandarias, Buenos Aires, 2005.

7 Sobre la participación del clero en el proceso de independencia y, particularmente, sobre el Congreso de 1816 y/o de Tucumán, ver: AYROLO, Valentina "Clero e independencia en las Provincias Unidas", Boletín de la Biblioteca del Congreso № 130 "Independencia. 200 años", Buenos Aires, 2016, en prensa; VERDO, Geneviève "Religião, 'espírito público' e patriotismo na independencia do Rio da Prata", Almanack, núm. 08, Guarulhos, 2do semestre 2014, pp. 104-119 y GUERRA OROZCO, Cecilia "El clero secular tucumano. Entre la legalidad y la legitimidad monárquica", en TÍO VALLEJO, Gabriela (coord.) La república extraordinaria. Tucumán en la primera mitad del siglo XIX, Prohistoria, Rosario, 2011, pp. 193-252. Ver también: DI STEFANO, Roberto El púlpito y la plaza: clero, sociedad y política de la monarquía católica a la república rosista, Siglo XXI Editores Argentina, Buenos Aires, 2004; DI STEFANO, Roberto y ZANATTA, Loris Historia de la Iglesia argentina. Desde la Conquista hasta fines del siglo XX, Grijalbo, Buenos Aires, 2000; PEIRE, Jaime El taller de los espejos. Iglesia e imaginario. 1767-1815, Ed. Claridad, Buenos Aires, 2000; AYROLO, Valentina Funcionarios de Dios y de la República. Clero y política en la experiencia de las autonomías provinciales, Biblos, Buenos Aires, 2007; CALVO, Nancy; DI STEFANO, Roberto y GALLO, Klaus (Coord.) Los curas de la revolución. Vidas de eclesiásticos en los orígenes de la Nación, Emecé Editores, Buenos Aires, 2002.
} 
Como dispusieron los diputados, el día 24 de marzo tuvo lugar una ceremonia semi-pública que siguió el rito tradicional de procesión de autoridades a través del centro ceremonial de la ciudad-conformado por la plaza y su entorno-, desde la "casa del Congreso" al templo de San Francisco para oír misa. En ese tramo, una gran multitud los acompañó con "universal regocijo", según la crónica de Fray Cayetano Rodríguez. Luego, los representantes se recluyeron en la sala de sesiones para elegir a sus autoridades y prestar juramento, comprometiéndose a "conservar y defender la religión Católica, Apostólica, Romana" y "promover todos los medios de conservar íntegro el territorio de las Provincias Unidas" ${ }^{8}$

El binomio "Patria" y "Religión" eran valores sociales cardinales cuya legitimidad se hundía en el tiempo y servían para expresar con gran emotividad la "profunda amistad", los "sentimientos" y los "lazos sagrados" que unían a estas jurisdicciones sin que por ello ninguna perdiera su particularidad y derechos. La misión del Congreso era, justamente, sancionar leyes que respetasen esta condición, la cual aparecía también en el tratamiento protocolar y en la fórmula de obedecimiento: “¿Juráis a Dios nuestro Señor y prometéis a la Patria reconocer en el presente Congreso de Diputados la Soberanía de los pueblos que representan?"9 Esta fórmula afirmaba la concepción plural de la nación distando de la controvertida jura de 1813 que prometía obediencia a "la autoridad soberana de las Provincias Unidas del río de la Plata" pudiendo -como se buscó- referir a una soberanía unitaria e indivisible y no a una agregación de soberanías provinciales en un cuerpo superior. El congreso de 1816, en cambio, inició sus sesiones con mucha cautela y difundió en todos los pueblos -por medio de oficios, prensa y Bandos-que su objetivo era el bien general y el de cada provincia sin que ninguno anulara al otro.

El 25 de marzo fue una jornada pública, en la que se celebró ostensiblemente la apertura del Congreso y el juramento de obediencia de las autoridades y corporaciones de Tucumán. Esta vez, un fastuoso cortejo acompañó a los diputados desde la sala de sesiones hasta el templo de San Francisco frente a una multitud más numerosa que la vista el día anterior. Las

${ }^{8}$ El congreso funcionó en una espaciosa residencia alquilada por el gobernador tucumano para tal fin a la señora Francisca Bazán de Laguna -actual Casa Histórica-, que la acondicionó para las multitudinarias sesiones. Las crónicas afirman que casi siempre, y en especial cuando se declaró la independencia, galerías, patio y la calle "del congreso" -antes "de la matriz"estuvieron atestados de gente (GIANELLO, Leoncio Historia del Congreso de Tucumán, Troquel, Buenos Aires, 1968, pp. 132-133; Álbum General de la Provincia de Tucumán en el 1ํo Centenario de la Independencia Argentina 1816-1916, publicación oficial, Buenos Aires, 1916.)

${ }^{9}$ El Redactor..., cit., núm. 1, Tratamiento Protocolar: “En honor de los Pueblos, verdadero origen de la Soberanía, sus representantes, como su viva imagen y expresión de sus votos reunidos en Congreso, tendrán el tratamiento de Soberano Señor en todas las ocasiones que se dirija la palabra a este respetable cuerpo" (misma fuente) 
milicias urbanas y rurales hicieron un cordón de honor cubriendo todo el recorrido, presentaron armas y batieron tambores mientras se escuchaban según El Redactor del Congreso Nacional-vivas y aclamaciones públicas de júbilo ya que este suceso borraba "los tristes efectos de las pasadas desgracias" y daba "nueva vida a nuestras esperanzas". En el templo, ordenadas las autoridades y corporaciones según el protocolo tradicional, los congresales ocuparon el lugar preferencial. Se celebró misa, Tedeum y sermón que estuvo a cargo del representante de Catamarca. Luego de la función religiosa, la comitiva retornó al recinto de sesiones donde el presidente del Congreso emitió -según las crónicas- un vibrante discurso al público presente en la sala, galerías, patio y calle, tras lo cual, juraron las autoridades y corporaciones locales. Grandes despliegues se sucedieron después durante los cinco días de fiesta: corrida de toros, juego de cañas, luminarias, músicas y baile. Se ordenaron celebraciones similares en las demás ciudades que juraron subordinación a esta asamblea. ${ }^{10}$

Resulta significativa la contradicción entre el tipo de representación política que pretendió establecer el Reglamento de 1815 para la elección de los diputados de este Congreso y la que se expresó en su ceremonia de inauguración. El reglamento electoral introdujo el principio de representación individual proporcional a la cantidad de habitantes por provincia, desdeñando la representación corporativa que le correspondía a cada jurisdicción según su jerarquía territorial borbónica. Sin embargo, la jura de obedecimiento al Congreso no se limitó a los diputados, en quienes -según la citada reglamentación-, los pueblos habían delegado su soberanía; sino que fue necesario que las autoridades y corporaciones de cada ciudad juraran también. ${ }^{11}$ Evidentemente, los pueblos y sus corporaciones seguían siendo la fuente de la soberanía y no el ciudadano individual y de esta forma apareció en las fiestas, cuyo protocolo y programa recién descripto sigue al de las Juras Reales.

Las Juras Reales eran el acto público por medio del cual se reconocía y juraba obediencia a un nuevo soberano, por tanto, era el dispositivo ceremonial que construía el lazo político entre la comunidad y su gobernante. ${ }^{12}$ El mismo consistía, en líneas generales, en: desfile jerárquico de autoridades y corporaciones, función religiosa (con tedeum y sermón), regreso a las dependencias correspondientes para la jura de las autoridades y corporaciones -que al seguirse después del acto religioso reforzaba su carácter sacro-; y por

${ }^{10}$ El Redactor..., cit., núm 1; FURLONG, Guillermo "Diego León Villafañe...", cit., p. 185 (carta fechada: 7-VI-1816); Julio P. ÁVILA La ciudad arribeña..., cit., pp. 395-397; Documentos Tucumanos. Actas del Cabildo, Edición de Manuel Lizondo Borda, Universidad Nacional de Tucumán, Tucumán, 1939, T. I: 1810-1816, p. 330: 18-IV-1816. En adelante: AC, T. I.

${ }_{11}$ Sobre el obedecimiento de las ciudades al Congreso ver: GIANELLO, Leoncio Historia del Congreso..., cit., especialmente pp. 135-141.

${ }^{12}$ Otro ejemplo de adaptación del ritual antiguo al festejo y legitimación de la Independencia en ORTEMBERG, Pablo "La entrada de José de San Martín en Lima y la proclamación del 28 de julio: la negociación simbólica de la transición", Histórica, núm. XXXIII.2, 2009, pp. 65-108. 
último, grandes despliegues lúdicos en señal de regocijo y esplendor, en especial, las corridas de toros tan vinculadas en la cultura hispana a la asunción de un nuevo monarca. El novedoso principio de soberanía popular que hacía de la Asamblea un órgano representativo de base electoral (de ciudadanos o pueblos) no impedía el recurso ni la necesidad de inscribir el reconocimiento del Congreso como nuevo soberano, en un atávico ritual de continuidad del poder que por lo mismo permitía exorcizar miedos y brindar cierto margen de certidumbre.

Los festejos concurrieron a ese fin $\mathrm{y}$, en efecto, mientras funcionó el Congreso en Tucumán se sucedieron lucidas ceremonias y los aniversarios de mayo y del 24 de septiembre ${ }^{13}$ se festejaron grandiosamente en la ciudad. Esta actitud respondía también a un modo tradicional de "hacer política" mediante el cual las corporaciones urbanas expresaban adhesión pero también se hacían merecedoras de encomios y contra dones por parte de la autoridad superior celebrada. En este sentido, grandes expectativas se crearon en torno al Congreso; se esperaba que remontara la guerra, declarara la independencia y organizara el Estado en base a la igualdad de los pueblos. La comunidad tucumana era particularmente sensible al tema de la guerra, esperaba tanto el reconocimiento de lo ya obrado como el compromiso conjunto para el sostén del Ejército Auxiliar; y el modo correcto de exigirlo era mediante el ofrecimiento de grandes fiestas, que la ciudad desplegó a lo largo de todo el año dieciséis, aun a costa del grave endeudamiento de su Cabildo y vecindario. ${ }^{14}$

\section{Declaración, jura y festejo de la Independencia}

Uno de los principales objetivos del Congreso tuvo rápida concreción: la Independencia, en sesión del 9 de julio de 1816. Su celebración se llevó a acabo al día siguiente, con misa solemne, desfile cívico-militar y un gran baile para "el pueblo principal". El sermón estuvo a cargo del presbítero Pedro Ignacio Castro Barros, diputado de La Rioja. De este discurso solo se conoce el encabezado que resume el tema principal: "Las cadenas están rotas, somos ya libres". ${ }^{15}$ Los lugares preferenciales en el templo estuvieron reservados para el Director

${ }^{13}$ En Tucumán se instituyó la celebración del aniversario de la Batalla local de 1812 poco después de su suceso. Esta se festejaba junto con el tradicional día de la Virgen de Las Mercedes, puesto que el enfrentamiento y la victoria tuvieron lugar ese mismo día, el 24 de septiembre. Ver WLDE, Ana "Representaciones de la política pos revolucionaria. Un acercamiento a la liturgia republicana (1810-1853)", en Gabriela TÍO VALLEJO (coord.) La república extraordinaria...,cit., pp. 79-145.

${ }^{14}$ FURLONG, Guillermo "Diego León Villafañe...", cit. pp. 185-186 y AC, I, pp. 331-332 (2-V1816); pp. 333-334 (11-V-1816); p. 337 (10- VI-1816); p. 342 (20- VII-1816); AC, I, pp.348-349 (13IX y 7-XI-1816).

${ }^{15}$ FURLONG, Guillermo Castro Barros. Su actuación, Academia del Plata, Buenos Aires, 1961, T. II, p. 92. 
Supremo, Juan Martín de Pueyrredón -designado recientemente por el Congreso-; el Presidente del Congreso -en ese momento, Francisco Narciso Laprida, representante de San Juan-, y el gobernador de Tucumán, Bernabé Aráoz. Estas autoridades encabezaron también el desfile corporativo tradicional en torno a las calles principales "mientras las tropas rendían honores y los ciudadanos vitoreaban jubilosos". Por último, esa noche, el Ejército ofreció un baile al que asistieron los diputados, las autoridades políticas locales, la oficialidad y el vecindario principal de Tucumán. También las familias de alcurnia emigradas de Salta, Jujuy y el Alto Perú. ${ }^{16}$

Días más tarde se celebró la jura a la independencia, decisión que sobrevino solo después de un arduo debate entre los diputados. Algunos oradores expusieron que, si los pueblos habían delegado su soberanía en los diputados y prometido obediencia a las disposiciones del Congreso, no era necesaria su convalidación jurando la Independencia. Sin embargo, muchos representantes sostuvieron que esta declaración era tan trascendental que necesitaba la ratificación de las provincias $\mathrm{y}$, además, tal exteriorización fortalecería la unidad y renovaría el compromiso con la causa. Finalmente, el Congreso ordenó que todos juraran la Independencia. En primer lugar, lo harían los miembros de esa asamblea, luego, cada pueblo en el siguiente orden: primero sus autoridades políticas, corporaciones civiles, eclesiásticas y militares, y por último, la población general. ${ }^{17}$ Estas instancias respondían al protocolo de las Juras Reales que señalábamos antes, las cuales reservan un día para la jura de las autoridades y corporaciones y otro para la población general. En ambos días se realizó la procesión tradicional cívico-militar y la función religiosa con Tedeum que precedía a los juramentos. Y luego de estas solemnidades, se desplegaron músicas, bailes y divertimentos populares. Este juramento, inscripto en el tradicional rito católico de la monarquía, sellaba definitivamente el reemplazo de la antigua lealtad al rey por la defensa a muerte de "la libertad de las Provincias Unidas en Sud-América". ${ }^{18}$

Tanto la decisión de hacer jurar la independencia, como su obligatoriedad y la vehemencia de su texto expresan, no solo de una concepción

16 ARÁOZ DE LA MADRID, Gregorio Memorias del General Gregorio Aráoz de la Madrid, Biblioteca Ayacucho, Editorial-América, Madrid, s/f, p117; GROUSSAC, Paul El viaje intelectual. Impresiones de naturaleza y arte, Segunda Serie, Buenos Aires, 1920, pp. 306-307.

17 Circular enviada por el Congreso al Director Supremo a los gobernadores, tenientes de gobernadores y cabildos en MUSEO MITRE, Documentos de Belgrano, T. VII, p. 338 y 340.

${ }^{18}$ Fórmula completa: “ ¿Juráis por Dios Nuestro Señor y esta señal de cruz, promover y defender la libertad de las Provincias Unidas en Sud-América y su independencia del rey Fernando VII, sus sucesores y metrópolis, y de toda dominación extranjera? ¿Juráis a Dios Nuestro Señor y prometéis a la patria el sostén de estos derechos hasta con la vida, haberes y fama? Sí así lo hiciereis Dios os ayude, y si no, Él y la patria os hagan cargo" (El Redactor..., cit., núm. 6). Ver también BREDA, Emilio "Cómo se proclamó y juró la Independencia en Buenos Aires y las provincias", en Guillermo Furlong et al El Congreso de Tucumán, Buenos Aires, 1966, pp. 194-195. 
todavía ambigua de los mecanismos de representación y de los límites de la delegación de la soberanía popular, sino la irreversibilidad de esta opción y la intimidación a todos -corporaciones e individuos-, a sostenerla "hasta con su vida". Esta última frase dista de ser una mera fórmula recurrente y, de hecho, está ausente en otros juramentos de independencia como el de Perú de 1821. ${ }^{19}$ El juramento celebrado en las ciudades que reconocían al Congreso reunido en Tucumán remite a un compromiso absoluto contra la incontrolable y desconocida deriva de la historia. Según Mona Ozouf, este tipo de juramentos se funda en el miedo a la doble imposibilidad de dar marcha atrás o de tener otro futuro diferente del que se repite en la jura. ${ }^{20}$ En el Río de la Plata, ese miedo plantó sus raíces en la incertidumbre sobre el resultado de la guerra, sobre la unión y gobernabilidad de las provincias y en la certeza de que no había más alternativas que la independencia o perecer en manos de los leales a la monarquía hispana. Ese compromiso se contrajo en nombre de los valores más profundos y tradicionales de la sociedad: Dios y la Patria.

También se dispuso la masiva difusión del Acta de Declaración de la Independencia a través de todos los periódicos de la época y la impresión de tres mil ejemplares de la misma en español, quichua y aymará con la intención de que nadie pudiera ignorar la declaración del Congreso. ${ }^{21}$

En Tucumán -por decisión de los diputados-, el gobernador; el Cabildo; los altos mandos militares y las órdenes religiosas locales juraron la independencia en la misma ceremonia que los representantes de la Asamblea, el día 21 de julio en la sala de sesiones. Aquella ceremonia, a pesar de tratarse de un rito restringido, fue presenciada por un "crecido número de ciudadanos", según El Redactor del Congreso Nacional. La ciudadanía, fundamento de la soberanía, no podía estar ausente. El Ejército Auxiliar, acuartelado en el pueblo de Trancas, hizo lo propio ese mismo día en la plaza principal de la villa. En cambio, las tropas locales y la población general de la provincia lo hicieron en una grandiosa ceremonia pública el día 25 de julio en el Campo de Honor. ${ }^{22}$ Quizá por no haberse realizado en la plaza principal de la ciudad, como era la costumbre, esta fiesta no siguió la ortodoxia colonial.

Las coordenadas de la jura popular no fueron casuales. El día 25 se escogió en honor a mayo de 1810, el mes debía ser el mismo en el que se declaró la independencia en la provincia y el emplazamiento, donde ocurrió la célebre

${ }^{19}$ ORTEMBERG, Pablo “La entrada de José de San Martín en Lima...”, cit., p. 91.

20 OZOUF, Mona "La fiesta bajo la Revolución Francesa", en Jaques Le Goff y Pierre Nora Hacer la Historia. III. Objetos Nuevos, Ed. Laia/Barcelona, Barcelona, 1980, p. 280.

${ }^{21}$ El Redactor..., cit., núm. 6.

${ }^{22}$ El Redactor..., cit., núm. 6. Los actos de la Jura -en el recinto del Congreso y en el Campo de Honor-fueron las instancias centrales de los 8 días de fiesta que decretó el gobernador de Tucumán: AC, I, 1-VIII-1816, pp. 343-344. BREDA, Emilio “Cómo se proclamó...", cit. pp. 195196 y $215-216$. 
Batalla de 1812. De esta forma, se concatenaron simbólicamente el inicio de la "regeneración política", su defensa armada por parte de Tucumán, que ahora también era sede del Congreso y primer pueblo en jurar la independencia. Según las crónicas, miles de milicianos armados y a caballo se presentaron en perfecto orden frente a los diputados del Congreso y ante una gran multitud, la cual asistía conmovida a la llanura en donde cuatro años antes había derrotado a las tropas de Lima y ahora recibía los encomios de los vehementes discursos de Bernabé Aráoz y Manuel Belgrano; ambos protagonistas de aquella batalla.

En ese marco, la alocución del gobernador Aráoz exigió a los tucumanos total subordinación al Congreso pero bajo una condición expresada de manera más o menos velada: que las resoluciones de ese cuerpo condujeran "a la igualdad entre los pueblos". Belgrano, por su lado, intervino para hacer pública su moción por una monarquía constitucional incaica, afirmando que en tal alternativa yacía la fecundidad del sacrificio de sangre que la comunidad tucumana habían realizado en 1812 bajo su dirección. Ambos oradores calcularon provocar una ferviente acogida de estos planteos por parte del público y con ello influir a los diputados que habían comenzado a debatir sobre la forma de gobierno. ${ }^{23}$

El rol desempeñado por la población y la tropa local en aquella celebración fue paradigmático. El festejo no solo puso en contacto a los asistentes con el debate político del momento, sino que los reconoció expresamente como fuente de la soberanía. Su interpelación y la conquista de su voluntad aparecieron como requisitos indispensables para definir el curso de la política. La ceremonia realizada el 25 de julio de 1816 presentó otra característica hasta entonces inusual y que se repetirá en fiestas similares: la concurrencia irrestricta, citada en un lugar público completamente abierto, sin barreras físicas antepuestas entre los habitantes, recreando simbólicamente la igualdad entre los ciudadanos que proclamaba el nuevo orden. Aparentemente,

${ }^{23}$ Los actos de la Jura -en el recinto del Congreso y en el Campo de Honor- fueron las instancias centrales de los 8 días de fiesta que decretó el gobernador de Tucumán: AC, I, pp. 343-344.

La ceremonia en el Campo de Honor fue descripta por el recuerdo de testigos de la época consignados por GROUSSAC, Paul "El Congreso de Tucumán", en El viaje intelectual..., cit. y por el cronista extranjero GRAANER, Jean Adam Las Provincias del Río de la Plata en 1816, El Ateneo, Buenos Aires, 1949, pp.65-66; estos autores señalan como fecha de la ceremonia pública el 25 de julio, esta fecha aparece consignada también en la proclama que Araoz pronunció en aquella ocasión (Discurso. 25-VII- 1816: de Bernabé Aráoz al Valeroso Regimiento de Tucumán, AGN, sala X, 5.10.7; transcripto por PÁEZ DE LA TORRE, Carlos Historia de Tucumán, Plus ultra, Buenos Aires, 1987, p.243-244) Pero hay autores que manejan otras fechas: ÁVILA, Julio P. La ciudad arribeña..., cit., p. 400, indica que fue el día 26 de julio, y otros historiadores -en base a la fecha con la que aparece copiada la proclama dicha por Belgrano en aquel acto-, sostienen que se realizó el 27 de julio (ver los capítulos de MELLI, Oscar Ricardo "San Martín, Belgrano, Güemes y el Congreso de Tucumán” y MEDRANO, Samuel W. “¿Monarquía o república?”, en Furlong, Guillermo et al, El Congreso de Tucumán..., cit., pp. 245 y 291, respectivamente). 
este protocolo de jura se mantuvo en todas las ciudades que prometieron la independencia, pero faltan más estudios específicos al respecto. ${ }^{24}$

El debate sobre la forma de gobierno que los discursos de Aráoz y Belgrano hicieron trascender a la escena pública tucumana, tornó más frecuente el uso del concepto "nación". En el Congreso se advirtieron distintas concepciones respecto de la misma, que redundaron en diferentes propuestas sobre la distribución territorial de la soberanía. Como resultaba extendida la idea de que las Leyes y el Gobierno que el Congreso adoptara debían respetar la "naturaleza" de la "nación", la cuestión radicó en definir cuál era esta. Tradicionalmente, "nación" refirió a una entidad corporativa conformada por distintos cuerpos reunidos bajo un mismo gobierno y leyes. La partición mínima de ese conjunto era la ciudad y su jurisdicción. Pero para otros, partidarios de una concepción unitaria de nación que era nueva en Hispanoamérica, las partes (o pueblos) se fundían en un todo indiviso, único y general. Para los adeptos a la primera posición, que eran entonces muy numerosos, la concepción unitaria de nación era una aberración, puesto que no concebían posible ni deseable la anulación de los pueblos particulares que habían pactado su reunión en un cuerpo superior. ${ }^{25}$ Por eso cuando las deliberaciones y ciertas medidas del Congreso -en especial la Constitución de 1819- avanzaron contra ese pacto, la unión de las provincias volvió a hacer crisis.

Si tenemos en cuenta esto último y el acto popular del 25 de julio de 1816, podría decirse que, cuando Aráoz rompió la subordinación de Tucumán al gobierno central en noviembre de 1819, estaba cumpliendo con la advertencia que dijera durante la jura popular del año dieciséis, fundada en esa concepción plural de nación, integrada por pueblos soberanos.

\section{Celebrar la revolución para dar principio al orden}

El 1ํ de agosto de 1816, el Congreso emitió un manifiesto a "las Provincias Unidas de Sud América excitando a los Pueblos a la unión y al orden" junto a un decreto titulado "Fin de la revolución, principio al orden, reconocimiento, obediencia y respeto a la autoridad soberana de las provincias y pueblos representados en el Congreso". Ambos documentos respondían al preocupante

${ }^{24}$ MUNILLA, María Lía Celebrar y gobernar...cit., capítulo II; BREDA, Emilio “Cómo se proclamó...", cit. Este autor refiere la ceremonia de jura de las autoridades y corporaciones locales de todas las ciudades que reconocían al Congreso de 1816 pero, con la sola excepción de Buenos Aires, omite las ceremonias de jura popular.

${ }^{25}$ Sobre el concepto de "nación" en el Río de la Plata ver: CHIARAMONTE, José Carlos Ciudades, provincias, estados: orígenes de la Nación Argentina (1800-1846), Ariel, Buenos Aires, 2007 y GOLDMAN, Noemí y SOUTO, Nora "De los usos a los conceptos de "nación” y la formación del espacio político en el Río de la Plata (1810-1827)", Secuencia, núm. 37, enero-abril 1997, pp. 35-56. 
grado de disolución que la militarización y la propagación del principio de retroversión de la soberanía a los pueblos estaba provocando en las provincias rioplatenses.

Las mencionadas disposiciones instaban a las jurisdicciones provinciales a presentar sus demandas ante el Congreso para que este las resolviera evitando conflictos y desunión. La guerra independentista no había terminado y los diputados entendían que los enfrentamientos interprovinciales hacían peligrar su resultado. Quienes se resistieran a este mandato serían reputados "enemigos del Estado" y castigados "con todo el rigor de las penas hasta la de muerte". El manifiesto y su decreto fueron impresos y ampliamente difundidos en todas las provincias, pero además, la liturgia política del período se estructuró en torno a la consigna de que, con la declaración de la independencia, la revolución había terminado y ahora era el momento de restablecer el orden. ${ }^{26}$

En Tucumán, Belgrano fue el principal encargado de la ejecución de este mandato. El Congreso lo había colocado nuevamente al frente del Ejército Auxiliar y desde allí aseguró la gobernación para uno de sus favoritos, el coronel Feliciano de la Mota Botello, desplazando a Aráoz que le había presentado competencia. Siendo Belgrano el jefe de hecho de la jurisdicción, la liturgia política local como así también la mayoría de los asuntos de gobierno, estuvieron bajo su estrecha supervisión, expresando la más perfecta subordinación al Régimen Directorial y el matiz de clausura de la Revolución que decretó el Congreso.

En esta línea se inscribieron numerosas iniciativas del General, como la imposición en los documentos públicos de un doble fechado que tuvo por referencias al 25 mayo de 1810 y al 9 de julio de 1816. El gesto de contar el tiempo de nuevo, como si 1810 y 1816 fueran el año cero, se mantuvo constante hasta 1819; luego reaparecerá intermitentemente. ${ }^{27}$ La doble efeméride patria también estaba presente en el calendario público para consolidar la ficción de comienzo y fin de la revolución.

En efecto, las conmemoraciones anuales en lugar de representar el recuerdo del proceso vivido, inventaron un pasado arquetípico de nuestra "Historia Civil" orientado a contrarrestar las amenazadoras derivas de la tensa alianza entre las ciudades. El resultado fue un relato cerrado y coherente que tuvo por objetivo inicial y desenlace la libertad política. En el caso de Tucumán

${ }^{26}$ El Redactor..., cit., núm. 11 y GACETA DE BUENOS AIRES, Reimpresión facsimilar dirigida por la Junta de Historia y Numismática Americana, Compañía Sud- Americana de Billetes de Banco, núm. 70, Buenos Aires, 1911-1914, T. IV, (31-VIII-1816), pp. 601-602.

27 Ejemplo: “En esta Capital de San Miguel de Tucumán a dos días del mes de Enero de mil ochocientos diez y siete, año octavo de la libertad y segundo de la independencia de la América del Sud", AC, II, p. 13 (2-I-1817) El subrayado es nuestro. Las actas capitulares se fecharon de este modo hasta su extinción. 
se celebraron: las Fiestas Mayas, que rememoraban "nuestro primer grito de libertad" o el comienzo de "nuestra regeneración política"; los festejos del 24 de septiembre, que recordaban la victoria local sobre el despotismo español asegurando la continuidad del proceso libertario; y el 9 de julio, que honraba el fin de la revolución por la consecución formal e irreversible de la independencia. ${ }^{28}$ Pero en realidad, la emancipación política había sido solo el objetivo de máxima y las convulsiones continuaron formando parte del proceso de construcción estatal.

Luego de la declaración de Independencia, el concepto "revolución" apareció alguna que otra vez en el discurso público de la provincia, pero su uso siguió siendo poco frecuente. Fue más usual la utilización del concepto de "regeneración política", que refería a una restauración de signo positivo como la que se entendía había comenzado en mayo de 1810. Su legitimación se inscribía en la lógica de la reparación o recuperación de unos derechos violentamente avasallados por los españoles y su rey. Como eran derechos que se habían tenido antes, no había ruptura, ni rebeldía, sino restitución. Esta lógica del restablecimiento, a mediados de la década de 1810, se avenía muy bien con la aspiración a una independencia política -presentada como única alternativa tras la obstinación del Rey contra los americanos- que mantuviera al orden socio-económico anterior prácticamente intacto. Por otro lado, el imaginario regeneracionista ubicaba la teoría de los Derechos del Hombre en un continuo simbólico que vinculaba al pasado precolombino -bastante idealizado- con los americanos de comienzos del XIX. La repetición canónica de este relato -en los sermones patrióticos por ejemplo- inscribía estas ideas en la larga duración, ganando con ello gran legitimidad.

En cambio, la politización que experimentó el concepto de "revolución" hizo que este tuviera connotaciones negativas respecto de la radicalidad y el alcance de los movimientos que pudiera referir. Si bien estas temidas derivaciones intentaban contenerse con el acompañamiento de adjetivos tales como "justa", "benéfica", "interesantísima" o "feliz", la expresión "regeneración política" no los precisaba y quizá por ello continuó siendo más utilizada. De todas formas, la concitada "libertad" o la regeneración superadora obrada por "Las Luces" y la independencia podían -en el acelerado y contingente tiempo de la política-, corromperse, degenerando la libertad en libertinaje e irreligión. En un régimen de historicidad que poseía aún

\footnotetext{
${ }^{28}$ La expresión "Historia Civil" corresponde al acta capitular que asienta la adquisición de la obra histórica del Deán Funes (AC, T. II, p. 118; 25-VIII-1818). Las representaciones de la revolución que aludimos se recogieron de sermones, proclamas, Bandos y disposiciones relativas a las celebraciones cívicas de la época en Tucumán. El programa de estas fiestas fue idéntico al de años anteriores: ornato del templo, plaza, edificios y calles principales, iluminación, función religiosa, enarbolamiento de la bandera, procesión de Las Mercedes (el 24 de septiembre) y por la tarde bailes y divertimentos populares.
} 
figuraciones cíclicas, el retroceso negativo era una posibilidad. El abuso de la libertad llevaba al "desorden, la división y la indiferencia" recayéndose nuevamente en la tiranía. Por ello, el referido lenguaje de la libertad era utilizado en estos años, no tanto para justificar la ruptura con las autoridades peninsulares y la guerra contra los sus fidelistas (porque esto podía seguir legitimando rupturas y convulsiones al infinito entre los pueblos), sino para dar por finalizar la "carrera por la libertad" y en adelante solo conmemorarla como parte de un glorioso pasado cuyo legado era un nuevo tiempo de orden, unión y progreso. Sobre todo cuando entre 1817 y 1819, la libertad parecía más amenazada por el peligro de disolución interna que por la tiranía extranjera. ${ }^{29}$

El énfasis puesto en el orden y en la unión no implicaba que la liturgia política del período negara la existencia de las convulsiones entre los pueblos; sino que les restaba legitimidad. Los enfrentamientos entre las provincias no se explicaban por causas racionales dado que esa unión no era concebida como una construcción artificial y política -y por tanto, perfectible-, sino como un hecho natural y evidente. En consecuencia, cualquier disturbio solo podía ser negativo y obedecer a defectos de carácter (egoísmos, odios personales, indiferencia y el supuesto desacostumbramiento de los pueblos a obedecer en un marco de libertad).

La liturgia regeneracionista ostentaba una representación naturalizadora del vínculo inter-jurisdiccional anclando una identificación transregional que, si bien no tenía una referencia territorial definida ni un gentilicio que la nombrara unívocamente, aparecía recurrentemente en el discurso público mediante el uso de metáforas familiares o de la naturaleza como aquella que refería a las comarcas rioplatenses como hermanas (y por lo tanto, la guerra entre ellas era fratricida), o como órganos o miembros de un mismo cuerpo (cuya desagregación causaba debilidad, disfuncionalidad o incluso la muerte), o como ramas de un mismo árbol (que si estaban juntas podían resistir tempestades pero si se hallaban dispersas, una ligera brisa era capaz de destrozarlas). Todas estas analogías apuntaban a presentar la unión de las "provincias del Sud" como un hecho inherente a su propia existencia.

29 Seguimos las expresiones con las que se intentó nombrar y significar la revolución en Tucumán desde los siguientes documentos y textos: AC, I, pp. 257-258 (8-V- 1815); 288 (25-IX1815); 331-334 (2 y 11-V-1816); 337 (10- VI-1816); 342 (20- VII-1816); 348-349 (13-IX y 7-XI-1816); AC, II, p. 13 (2-I-1817); 26-27 (26-II-1817); AC, II, p. 28 (3-III-1817); p. 164-165 (25-V-1819); El Redactor..., cit., núm. 1; Guillermo FURLONG “Diego León Villafañe...”, cit. pp. 185-186; “Libro Copiador del Ejército del Perú. Cuaderno núm. II. Superior Gobierno. núm. 71”, en Documentos del Archivo de Belgrano, Museo Mitre, Imprenta de Coni Hnos., Buenos Aires, 1914, Tomo IV, p. 346; Discurso. 25-VII- 1816: de Bernabé Aráoz...cit.; CASTRO BARROS, Ignacio “Oración patriótica del 25 de mayo de 1815 en la ciudad de Tucumán", IRIARTE, Felipe A. "Oración patriótica del 25 de mayo de 1817 en la ciudad de Tucumán” y "Oración patriótica con motivo de los gloriosos triunfos de nuestras armas en Chile en 1817", en: CARRANZA, Adolfo P. El Clero argentino..., cit. 
La exaltación de la fraternidad entre las provincias se dio de manera paralela al ensalzamiento de la comunidad local. En Tucumán, los ritos del 24 de septiembre y del 9 de julio, por ejemplo, celebraron la unión y la subordinación a la causa del gobierno central con todo el brillo que la ciudad pudo permitirse pero, en esa representación, la comunidad local siempre desempeñó un rol particular, diferenciado, autónomo y encomiástico, ya sea como "Sepulcro de la tiranía", sede del Congreso que declaró la Independencia o primer pueblo en jurarla.

Este tipo de construcción, que naturalizaba una identidad transregional mediante la reafirmación de la local, no era en absoluto privativo de Tucumán. En Salta, por ejemplo, las celebraciones mayas adquirieron gran despliegue y su exaltación estuvo asociada al encumbramiento del patriotismo militar local, enarbolando títulos como "los vencedores" o "los decididos de Salta". Estos galardones eran aún más significativos desde que la comunidad local pertenecía a un cuerpo superior cuya independencia se sostenía en la particular constancia del pueblo salteño -y en la dirección de Güemes-. ${ }^{30}$

No solo las fiestas regulares concurrieron a fijar la revolución en el ritual dándole sentido de clausura e intentando su remoción del tiempo de la política, sino también las celebraciones coyunturales, es decir, aquellas que tenían lugar solo una vez.

Las victorias sanmartinianas y las represiones a movimientos autonomistas fueron celebradas únicamente en el año de su ocurrencia y se realizaron como constataciones del triunfo y finalización de la "revolución". Cuando a fines de 1816 fue reprimido el levantamiento del coronel Juan Francisco Borges en Santiago del Estero, las tropas del Ejército Auxiliar comisionadas a tal fin por el Congreso, fueron recibidas en Tucumán con lucido acto público y condecoradas con un escudo en paño azul que rezaba "Honor a los restauradores del orden". ${ }^{31}$ Las victorias del Ejército de los Andes en Chacabuco y Maipú, por su lado, fueron también festejadas como la ratificación de la revolución triunfante en el Río de la Plata.

Los festejos realizados en Tucumán por las victorias en Chile pusieron a la ciudad en contacto con un espacio político-independentista más extenso y con el recuerdo de su glorioso pasado militar. En este sentido, los servicios religiosos correspondientes se realizaron en el templo de La Merced, explícitamente por ser esta la Generala del Ejército Auxiliar; título que adquirió

30 Algunos aspectos de la liturgia revolucionaria de Salta en: VERDO, Geneviève "La Bannière..." cit. y en BRAGONI, Beatriz y MATA DE LÓPEZ, Sara "Militarización e identidades políticas en la revolución rioplatense", Anuario de Estudios Americanos, 64, 1, enerojunio, Sevilla, 2007, pp. 221-256. La reafirmación de una identidad transregional fortaleciendo la local también se dio en los pueblos fidelistas (ORTEMBERG, Pablo Rituales del Poder..., cit.)

${ }_{31}$ ARÁOZ DE LA MADRID, Gregorio Memorias..., cit., p. 120. La Madrid, coronel a cargo de aquella misión, remarcó que Belgrano costeó los premios. 
por iniciativa de Belgrano a causa de la victoria local de 1812. Expresaron también estas conexiones el sermón pronunciado por la victoria de Chacabuco y la colocación de la piedra angular de un monolito en honor al triunfo de Maipú, construido en el mismo campo de Batalla de aquel 24 de septiembre. Estas fiestas cumplieron, además, el objetivo de tranquilizar a la población respecto de la amenaza "realista" asentada en Jujuy -dado que ahora todas las energías del enemigo se concentrarían en el avance de San Martin-, y el de distraer la opinión pública y moralizar al Ejército del Norte que se hallaba inmovilizado en Tucumán y alejado de sus tareas profesionales. ${ }^{32}$

Estas celebraciones registraron varias noches de iluminación y "regocijos públicos", misa solemne con canto de Tedeum y honores extraordinarios a San Martín; a quien el cabildo tucumano calificó de "héroe memorable" y lo nombró "Regidor más antiguo" con voto perpetuo. Ordenó, además, esculpir una placa con aquel título para que fuera colocada en la Sala Capitular..$^{33}$

El sermón pronunciado por la victoria de Chacabuco en 1817, a cargo de Felipe Antonio de Iriarte, describió el alma de José de San Martín como confiable, "noble, generosa y heroica" y a él como un hombre de "Patriotismo inimitable, pericia militar, conocimientos políticos, vigilancia, valor $\mathrm{y}$ constancia". Este catálogo de virtudes brilló aún más gracias al contrapunto que ofrecían sus contendientes: José Fernando de Abascal y Joaquín de la Pezuela, a quienes el oficiante asignó las calidades de déspotas, opresores, tiranos, ambiciosos, egoístas, alucinadores, envidiosos, impolíticos y sanguinarios. Abascal, además, fue calificado como espíritu insensible y carente de talentos. ${ }^{34}$

32 Cabe tener en cuenta que muchos sucesos de armas no pasaban de ser anunciados por Bando y festejarse con luminarias del Cabildo, lo cual respondía por lo general a órdenes del gobierno central. Pero cuando los triunfos eran cercanos a la jurisdicción -ya sea geográficamente o porque el jefe victorioso tuvo alguna relación con la comunidad territorial, como el caso de San Martín que fue jefe militar en Tucumán en 1814-, se celebraron más espontáneamente, es decir, por iniciativa de las autoridades locales antecedida frecuentemente por el súbito júbilo de la población al arribo o anuncio de la noticia. Sobre los festejos de las victorias sanmartinianas en Tucumán: PAZ, José María Memorias póstumas del General José María Paz, La Discusión, La Plata, 1892, T. I, pp. 321-322 y FURLONG, Guillermo “Diego León Villafañe...”, cit., pp. 190-191. El general Tomás de Iriarte, de paso por Tucumán en 1818, comentó que el ejército estaba mal pago, alejado de su labor profesional y dedicado a tareas agrícolas para su sustento (IRIARTE, Tomás Memorias, La independencia y la anarquía, Buenos Aires, 1946, p. 126).

${ }^{33}$ Honras al Gral. José de San Martín en Tucumán: AC, T. II, p. 26-27; 28; 106; 113; OFICIO: El Cabildo agradece a San Martín su triunfo en Chile: Archivo Histórico de Tucumán, Sección Administrativa, Tomo 26, folios 272-272v (borrador, 24-IV-1818); PAZ, José M. Memorias..., cit., p. 322. En Tucumán también se ensalzó al Gral. Belgrano (PAZ, José M. Memorias..., cit., pp. 297-298), al Coronel don Gregorio Aráoz de Lamadrid -“desembarazado guerrero emprendedor"-; al "memorable cura de la catedral del Cuzco", Dr. Idelfonso Muñecas, a quién "la fiera pésima lo devoró" y al militar Diego González Balcarce (CARRANZA, Adolfo P. El Clero argentino (1810-1830), Buenos Aires, 1907, T. II, pp 213-214; 219 y 37-43, respectivamente)

${ }^{34}$ IRIARTE, Felipe A. “Oración patriótica...", cit., pp. 257; 263-264. 
Es notable que las virtudes y los defectos estén definidos por el carácter, el mérito político y la inteligencia, y no por la fe. El enemigo señalado por Iriarte mereció toda clase de insultos más no el título de hereje, tampoco la religiosidad de San Martín fue destacada especialmente. Este sermón se distingue de los celebrados en años anteriores por su fuerte y decidida impronta moderna y local; ya que la constante función moralizadora y legitimadora de esta Oración Patriótica no se asienta en la referencia a guerreros bíblicos o a la salvífica intervención divina, sino que en su arenga, el héroe y el villano, las virtudes y los defectos se encarnan en conocidos personajes de la época. Los hechos de guerra referidos no son los del Antiguo Testamento ni los de la Antigüedad Clásica sino los cercanos eventos de Chile y el Alto Perú. El éxito militar no se debía a la Providencia, sino al genio de San Martín y a la cuidada preparación del Ejército de Cuyo. La justificación de la guerra no yacía en los designios divinos sino en la defensa de los Derechos del Hombre y del imprescriptible pacto social entre gobernantes y gobernados. Siguiendo esa lógica, el orador promovió una restitución constitucional de la dinastía incaica y exaltó a la comunidad local afirmando que el triunfo de Chacabuco había sido posible gracias a la resistencia de Tucumán y al acantonamiento del Ejército Auxiliar en su ciudad, en prevención de cualquier avance del Perú. ${ }^{35}$

En suma, el discurso de Iriarte presentó, además de un rotundo aval a la posición y gestión política de Belgrano, profusas loas al patriotismo local y al heroísmo militar de San Martín, patriota modelo, junto a una interpretación visiblemente más secular y localizada de las fuerzas determinantes del curso histórico.

Al año siguiente, durante los festejos por el triunfo de Maipú, Belgrano hizo colocar la piedra basal del primer monumento patrio que tuvo Tucumán. Se trató de una pirámide permanente levantada en el sitio donde los tucumanos y el Ejército Auxiliar vencieron, el 24 de septiembre de 1812, a las tropas de Lima. Por su disposición, este monolito rindió homenaje a las victorias de la patria sobre la tiranía, a los ejércitos Auxiliar y de Los Andes, al patriotismo de los pueblos que combatieron en Tucumán en 1812 y en Chile en 1818 y al mérito de sus jefes: Belgrano y San Martín. La ostentación de una victoria militar y del desempeño local de personajes ilustres constituía importantes notas de distinción para las ciudades, de ahí su recurrente evocación. ${ }^{36}$

35 IRIARTE, Felipe A. “Oración patriótica...”, cit., pp. 256; 258; 262-265 y 271-273.

${ }^{36}$ El monumento de Tucumán de 1818 es referido por PAZ, José M. Memorias..., cit., p. 322. Otro importante gesto destinado a exaltar el rol de Tucumán en el proceso independentista, especialmente, su patriotismo militar, fue su nuevo Escudo diseñado en 1816 -probablemente inspirado por Belgrano- y utilizado profusamente hasta 1819, ver: WILDE, Ana Celebrar la regeneración de la república. La liturgia política en Tucumán durante la primera mitad del siglo XIX, Tesis Doctoral inédita, Universidad Torcuato Di Tella, Buenos Aires, diciembre de 2014, capítulo 4 . 
No se conservan imágenes ni descripciones detalladas de este monolito, aparentemente muy sencillo pero de igual modo excepcional. Los monumentos permanentes vinculados a la regeneración política o a la independencia americana no fueron para nada frecuentes en la década de 1810 en el Río de la Plata ni en América del Sur. Si bien proyectos no faltaron, la guerra, la escasez económica y la inestabilidad política los postergaron indefinidamente. La Pirámide de Tucumán de 1818, en seguro diálogo con la de Buenos Aires de 1811 y la de Salta de 1813 (también levantada por Belgrano en el campo de Batalla local), rememoraba la revolución y la guerra que, "concluida" en el Río de la Plata con la declaración de Independencia, se desplazaba hacia Chile y Perú en aras del mismo resultado. Por otro lado, el rito de colocación de la piedra angular de este tipo de monumentos simbolizaba el comienzo de una nueva era, pretendidamente signada por la libertad y el orden, en la que los ciudadanos se desempeñarían como "árbitros de su propio destino". ${ }^{37}$

Además de las fiestas por victorias militares, los aniversarios patrios y las condecoraciones públicas, las imágenes y mensajes de pedagogía cívica se desplegaron también por medio de Bandos públicos, proclamas, ediciones del Diario Militar del Ejército Auxiliar del Perú (primer periódico de la región), e impresos cívicos que mandaba a distribuir Belgrano (como el manifiesto de la independencia de Venezuela, por ejemplo). De este conjunto de expresiones litúrgicas de la política del período, destacaremos las Fiestas Mayas de 1819 porque constituyen la muestra más clara de un desplazamiento que viene tomando forma desde el advenimiento de la Independencia: el traslado del centro de preocupación desde el enemigo "externo" -la tiranía española- a la necesidad de "burlar" a un enemigo interno interesado en la disolución del cuerpo político de las Provincias Unidas. La peligrosidad de este enemigo -o la fragilidad de la ficción de unión entre las ciudades-, emerge tanto de la descripción oficial de este aniversario como de la ceremonia de Jura de la Constitución de 1819 que tuvo lugar durante estas fiestas mediante un ritual todavía más fortificado que el de la Jura de Independencia. En efecto, no bastó la jura de los diputados, ni de las autoridades y corporaciones de cada ciudad, ni la jura popular por aclamación en ceremonia pública; sino que además se exigió que cada jefe militar y cada oficial juraran individualmente frente a un

37 Cabe aclarar que así como no se conservan descripciones detalladas sobre la Pirámide de Tucumán, tampoco las hay respecto del adorno de la plaza en ocasión de fiesta, más allá de referencias a arcos de flores y adornos celestes y blancos y otras observaciones que citamos oportunamente, todo lo cual marca un gran contraste con las arquitecturas efímeras y demás despliegues que sabemos se realizaron en las ex capitales coloniales de Buenos Aires (sobre cuya Pirámide y arte efímero Munilla posee un extenso análisis), Lima, Santiago o Santa Fe de Bogotá (MUNILLA, Lía Celebrar..., cit.; ORTEMBERG, Pablo Rituales...cit; VALENZUELA MÁRQUEZ, Jaime Fiesta, rito..., cit.; CALDERÓN, María Teresa y THIBAUD, Clément La majestad... cit., respectivamente). 
crucifijo, con una mano en el puño de su espada y la otra sobre los evangelios. ${ }^{38}$ Resultaba evidente entonces, no solo que la soberanía popular residía en todos lados y en ninguno de manera suficiente; sino que en 1819 el Congreso no contó, respecto de su obra constitucional, con el mismo consenso que tuvo tres años antes en torno a la emancipación política.

\section{Conclusiones}

El estudio realizado sobre las celebraciones y los sentidos que asumieron ciertos conceptos recurrentes en el discurso político público de Tucumán durante el segundo lustro de la década de 1810 permiten formular algunas consideraciones.

En primer lugar, señalar la acreditada pervivencia de ritos, fórmulas, matrices argumentales y formas de representación política propias del Antiguo Régimen, lo cual consolidó la configuración jerárquica y corporativa de la sociedad y del poder político. Aun el avance de un relato más secularizado y territorializado de la Revolución, que oportunamente indicamos en ciertas expresiones de la liturgia política, supuso torsiones pero no el quiebre de las representaciones tradicionales del mundo. No obstante esto, aquellas persistencias simbólicas fueron utilizadas también para dar sustento al nuevo principio de soberanía popular, a sus autoridades, ensayos institucionales y emblemas que, si se hubieran presentado despojados de toda tradición hubieran caído en el vacío simbólico y resultado ininteligibles y ajenos a la población que ahora era el nuevo sujeto de imputación de la soberanía. En otros aspectos, como el ritual de exaltación del protagonismo político y militar de los pueblos, el ensalzamiento de unos reconocidos pro-hombres y la recurrente mención de ciertos derechos y principios políticos en clave moderna, supusieron un cambio sensible respecto del anterior meta-relato comunitario de carácter cuasi cíclico y providencial que caracterizó las liturgias del poder durante el período hispánico.

Sobre este último punto, una de las consecuencias más complejas de la torsión hacia la secularización del curso histórico -y por tanto, de la representación del proceso independentista- fue la doble temporalidad que presentaron desde entonces las liturgias cívicas: la temporalidad política y la

${ }^{38}$ Relación oficial de las Fiestas Mayas de 1819 (AC, II, p. 164-165). Refiere la ceremonia del Juramento PAZ, José M. Memorias..., cit., p.348. Cuando el pacto era tan tenso y frágil, el ritual solía reforzarse con redundantes muestras de compromiso, Ortemberg lo muestra en Lima, en ocasión de la Jura de independencia de 1821, la cual debió ser suscripta, además, mediante la firma de los juramentados (ORTEMBERG, Pablo "La entrada de....", cit.) Para una reflexión sobre la noción de soberanía y nación subyacente en los juramentos que combinan el elemento corporativo y el individual ver: LORENTE, Marta "La Nación y las Españas", en Bartolomé Clavero, José María Portello y Marta Lorente Pueblos, Nación, Constitución (en torno a 1812), Ikusager Ediciones- Fundación para la Libertad, Málaga, 2004, pp. 101-142. 
ritual. Ambas concepciones del tiempo son antagónicas pero también necesariamente complementarias, según lo avistamos en los usos del concepto "revolución" y en el sentido paradójico de reactualización y clausura que tuvieron las celebraciones posindependentistas respecto del proceso y los principios revolucionarios.

En efecto, la función del ritual es des-historizar los hechos que conmemora, porque festejarlos regularmente supone arrancarlos del decurso cronológico y fijarlos en un calendario (cuyo tiempo es circular, controlado y recurrente), convirtiéndolos en tradición, mientras que sus implicancias políticas siguen en marcha habilitando nuevas transformaciones. No podía renunciarse a la evocación de la "revolución" política, por más inquietantes que fueran sus consecuencias, dado que de ella derivaba la legitimidad de las nuevas autoridades. Pero al mismo tiempo, estas últimas debían presentarse como instancia de estabilización y paz que, tras los primeros años de lucha, eran las demandas sociales más extendidas. Los gobiernos posindependientes se debatieron continuamente en este dilema de tener que legitimarse en la Revolución pero al mismo tiempo presentarse como alternativa de orden estable, predecible y segura.

Varias fueron las maneras mediante las cuales la nueva liturgia intentó saldar la paradoja entre cambio y estabilización: la representación del pasado comunitario sobre las coordenadas sociales tradicionales de patria y religión pero mediante un nuevo calendario que celebraba hechos inéditos y locales, de la política y la guerra; la pervivencia de los protocolos coloniales pero con algunas sutiles modificaciones para dar cabida y exaltar a las autoridades e instituciones surgidas del nuevo principio de legitimidad política; el sostenimiento de la tradicional identificación de los pueblos con su comunidad territorial pero dentro de un esquema de pertenencias y lealtades referido a un nuevo cuerpo político superior (el de las Provincias Unidas); el mantenimiento de la tradicional representación corporativa de la sociedad pero con un sensible incremento del componente militar y de elementos simbólicos de carácter marcial, los cuales encarnaron la otra cara de la soberanía popular: la del derecho y la obligación de tomar las armas en defensa de la libertad. La militarización de los rituales públicos incluyó también la configuración de un culto al héroe militar como paradigma cívico de obediencia y abnegación, además de funcionar como referente para la identificación de propios y enemigos en la nueva clave de los derechos del hombre y los pueblos para así poder aglutinar apoyos y legitimar represiones y puniciones a los rivales.

Sin embargo, la puesta en escena de estos elementos no configuró una representación homogénea del pasado ni del futuro de estas comunidades. Siempre aparecieron ciertas tensiones, incertidumbres o demandas que resquebrajaron la imagen de unanimidad y consenso que supuestamente las ceremonias debían brindar. La presencia de imágenes en conflicto o la 
expresión de suspicacias, gestos o argumentaciones reforzadas, son cuestiones esperables en las liturgias políticas puesto que al ser una dimensión clave y constitutiva del poder, su configuración y reconfiguración es siempre objeto de disputas; más aún en comunidades sometidas a fuertes y vertiginosos cambios donde la centralización de los rituales políticos es cuanto mucho un deseo y ningún sector tiene el pleno monopolio del ceremonial público.

Con todo, las máximas autoridades del período hicieron grandes esfuerzos por imponer un relato cerrado, coherente y cada vez más secularizado de la Revolución, en tanto hecho fundante de la nueva comunidad política del Río de la Plata. En este sentido vimos como las fiestas y los discursos públicos contaron un pasado común que comenzaba el 25 de mayo de 1810, día del "primer grito de libertad"; continuaba con los triunfos patriotas contra el despotismo en la guerra independentista (que en Tucumán se honraba anualmente mediante la conmemoración de la Batalla del 24 de septiembre de 1812) y culminaba con la Declaración de la Independencia el 9 de julio de 1816. Ese relato aparecía impulsado de principio a fin por un único objetivo supuestamente consensuado por todos desde el primer momento: la independencia; y proyectaba un futuro inminente de paz y progreso para la región siempre y cuando se mantuviera unida y subordinada al Congreso y a las autoridades que este reconociera como legítimas; caso contrario, este "camino" ascendente sufriría un retroceso, porque el legado de la Revolución se degeneraría y los pueblos recaerían en la tiranía y el desorden.

Esta historia compartida, que daba por clausurada la Revolución, propició una trascendente torsión de sentido en la antinomia de libertad vs tiranía que antes había sido central para promover la guerra contra la Monarquía hispana -caracterizada como despótica- y contra sus defensores, designados como "españoles" para extremar su alteridad. Justamente, desde la declaración de Independencia observamos que aquella dicotomía se resignificó en los nuevos opuestos de orden vs anarquía, que ocuparon un lugar cada vez más central en el dispositivo litúrgico promovido por el Congreso. Este deslizamiento de sentido redundó en la representación de un "nosotros" partidario de la libertad y defensores del orden legítimo contra unos enemigos internos definidos como anárquicos, egoístas, partidarios del despotismo y fratricidas.

Considero que esta internalización del conflicto expresa el parcial cumplimiento de aquella renegociación de la unión realizada entre 1815 y 1816; porque si bien la guerra contra el Perú se remontó -a partir del éxito de la estrategia sanmartiniana- y la emancipación política de la región se consolidó con la declaración de independencia; el objetivo de organizar el Estado en base a la igualdad de los pueblos había naufragado y la Carta de 1819 fue, en este sentido, el último desgarro que precipitó la alianza siempre zozobrante entre las ciudades. En adelante, se abriría un nuevo ciclo litúrgico abocado a construir y 
legitimar las autonomías provinciales recurriendo al legado simbólico de estos años, especialmente, a la citada dicotomía de orden-anarquía/tiranía que marcará el tono y el recrudecimiento de la violencia política de las próximas décadas.

Rosario, 30 de mayo de 2016. 